\title{
Adherence of Neutrophils to Canine Cardiac Myocytes In Vitro Is Dependent on Intercellular Adhesion Molecule-1
}

\author{
C. Wayne Smith, " Mark L. Entman, ${ }^{*}$ Caryl L. Lane, * Arthur L. Beaudet, \\ Keith Youker, " Hal K. Hawkins," and D. C. Anderson*" \\ *Speros P. Martel Laboratory of Leukocyte Biology, Departments of Pediatrics, ${ }^{\ddagger}$ Section of Cardiovascular Sciences, \\ The Methodist Hospital and The DeBakey Heart Center, Houston, Texas 77030; Department of Medicine, ${ }^{8}$ Howard Hughes Medical \\ Institute and Institute for Molecular Genetics, Houston, Texas 77030; and "Department of Pathology, 'Departments of Cell Biology, \\ and Microbiology and Immunology, Baylor College of Medicine, Houston, Texas 77030
}

\begin{abstract}
The adhesiveness of isolated canine cardiac myocytes for neutrophils is greatly increased by stimulation with cytokines such as tumor necrosis factor $\alpha(T N F \alpha)$. Since this adhesion is significantly inhibited by an anti-CD18 MAb, experiments were performed to test the hypothesis that the newly expressed adhesion molecule on the cardiac myocytes was intercellular adhesion molecule-1 (ICAM-1). A newly developed MAb, CL18/6, was found to exhibit the functional and binding characteristics with canine neutrophils and canine jugular vein endothelial cells expected of an antibody recognizing ICAM-1. MAb CL18/6 also bound to isolated cardiac myocytes after stimulation of the myocytes with cytokines, and it blocked by $>90 \%$ the adhesion of neutrophils to stimulated myocytes. A partial cDNA clone for canine ICAM-1 was isolated, and ICAM-1 mRNA was found to be increased in both endothelial cells and cardiac myocytes after cytokine stimulation. Cytokines that both increased the CL18/6-inhibitable adhesion of neutrophils to myocytes and induced expression of ICAM-1 were IL-1 $\beta$, TNF $\alpha$, and LPS. These results are consistent with the conclusion that canine endothelial cells and cardiac myocytes express ICAM-1 in response to cytokine stimulation, and that ICAM-1 functions as an adhesive molecule for neutrophils on both cell types. (J. Clin. Invest. 1991. 88:1216-1223.) Key words: neutrophil $\bullet$ myocyte $\cdot$ ICAM-1 $\bullet$ adhesion cytokines
\end{abstract}

\section{Introduction}

When ischemic myocardial tissue is reperfused with normally oxygenated blood, an inflammatory process rapidly ensues (1). Neutrophils accumulate in the tissue (2-5), and chemotactic activity appears in the lymph draining the previously ischemic myocardium (6). Experimental manipulations of animal models designed to remove neutrophils from the circulation (2, 7-10) or to inhibit their functions (1) have provided measurable reductions in the extent of myocardial damage after ischemia and reperfusion. Intercellular adherence appears to be necessary for leukocyte accumulation at sites of inflammation

Address correspondence to C. Wayne Smith, M.D., Texas Children's Hospital, Clinical Care Center, 6621 Fannin, Suite 1130, Houston, TX 77030. 1991.

Received for publication 29 May 1991 and in revised form 3 July

J. Clin. Invest.

(c) The American Society for Clinical Investigation, Inc.

$0021-9738 / 91 / 10 / 1216 / 08 \quad \$ 2.00$

Volume 88, October 1991, 1216-1223
(11). That this is true for neutrophils accumulating in the ischemic and reperfused myocardium is supported by recent studies using anti-CD18 MAbs. An anti-CD18 MAb (R3.3) reduced infarct size after $5 \mathrm{~h}$ of reperfusion in an ischemia/reperfusion model in rabbits (12). Another anti-CD18 MAb, 60.3, applied to radiolabeled rabbit neutrophils in vitro reduced their accumulation in rabbit heart following a 3-h reperfusion period (13). Studies in canine models of cardiac ischemia/reperfusion have revealed that anti-CD11b MAb 904 significantly diminished infarct size (14-16), and anti-CD18 MAbs MHM23 (17), IB4 (18), and R15.7 (19) are each capable of reducing neutrophil accumulation. Numerous studies have shown that neutrophil adhesion to endothelial cells is partially CD18-dependent (20-31).

In an effort to evaluate the possible roles of intercellular adhesion in myocardial inflammation, we have used canine cells in vitro to examine the adherence of neutrophils to endothelial cell monolayers and isolated cardiac myocytes. We found that canine neutrophils have little ability to adhere to either endothelial or myocardial cells unless a stimulus is applied $(6,26,32)$. CD18-dependent adherence of neutrophils to endothelial cells is markedly enhanced by stimulation of either cell type $(6,26,32)$. Adherence of neutrophils to myocytes is also significantly enhanced by stimulation of both cell types, and this adhesion is almost entirely CD18-dependent since it is inhibited by $>90 \%$ by anti-CD18 MAb R15.7 (32). The current report investigates the hypothesis that intercellular adhesion molecule 1 (ICAM-1) $)^{1}$ is expressed on cardiac myocytes after cytokine stimulation, and serves as a ligand for the CD18dependent adhesion of canine neutrophils. Previous studies have shown that ICAM-1 can be expressed on a wide array of cell types (33), and that it serves as a ligand for both CD1 1a/ CD18 (LFA-1) $(22,34,35)$ and CD1 1b/CD18 (Mac-1) $(22,36)$.

\section{Methods}

\section{Isolation of canine cardiac myocytes}

Healthy mongrel dogs weighing $10-15 \mathrm{~kg}$ were anesthetized using sodium pentobarbital. The heart was removed through the left lateral chest under sterile conditions, and immediately placed in ice cold saline. The aorta was then cannulated using a tubing adapter suitable for the individual heart, and the procedure for obtaining isolated myocytes was followed exactly as described previously (32). Preparations with a viability of $>80 \%$ were used in incubation experiments with neutro-

1. Abbreviations used in this paper: CJVEC, canine jugular vein endothelial cells; ICAM-1, intercellular adhesion molecule-1; PAF, platelet activating factor; PCR, polymerase chain reaction; rTNF $\alpha$, recombinant tumor necrosis factor $\alpha$; TNF $\alpha$, tumor necrosis factor $\alpha$; ZAS, zymosan activated canine serum. 
phils. Cells were then placed on ice and used within 1-2 d. Viability was not appreciably altered over this period.

\section{Neutrophil isolation}

Canine neutrophils were isolated from citrate anticoagulated venous blood using techniques previously described for the isolation of human neutrophils (22). This yielded a preparation of cells $>95 \%$ neutrophils with $>99 \%$ viability. These cells were suspended in Dulbecco's PBS and stored at $4^{\circ} \mathrm{C}$ for up to $4 \mathrm{~h}$.

\section{Monoclonal antibodies}

Monoclonal antibodies IgG1 (Damon Biotech, Needham Heights, MA) and 4A5 (IgG1, prepared as previously described) (22) without binding specificity for canine cells served as nonbinding controls. The anti-CD18 MAb R15.7 (IgG1) was provided by Dr. R. Rothlein (Boehringer Ingelheim Pharmaceuticals Inc., Ridgefield, CT). Two new MAbs, SG10G8 (IgG1) and SG2G8 (IgG1) against canine neutrophils were prepared using methods previously described (22). These antibodies bound to neutrophils at about the same level as R15.7, but did not bind to canine endothelial cells or myocytes. They served as binding controls in adhesion assays since they did not inhibit adhesion. Anti-canine endothelial antibodies were made by immunizing BALB/ c mice with endothelial cells that had been stimulated with LPS (10 $\mathrm{ng} / \mathrm{ml}$ ) for $4 \mathrm{~h}$, and subsequently preparing hybridomas as previously described (22). Supernatants were screened for the ability to bind to the surface of canine endothelial monolayers, and clones were selected for subsequent study if they exhibited increased binding to $4 \mathrm{~h}$ LPS stimulated endothelium. Two clones, CL18/1D8 (IgG1) and CL18/6 (IgG1) were selected. In preliminary studies CL18/6 was found to inhibit neutrophil adhesion to LPS stimulated endothelial cells, while CL18/1D8 did not. All MAbs were used in function studies as purified IgG. Another clone, $\mathrm{CL} 21 / 8 \mathrm{Cl}$ (IgG1), was selected as a control since binding of this MAb to endothelial cells was not altered by LPS stimulation.

\section{Immunoprecipitation studies}

Intact canine jugular vein endothelial cells were surface labeled with ${ }^{125}$ I by lactoperoxidase or glucose oxidase, solubilized in $2 \%$ NP-40, immunoprecipitated with CL18/6, CL18/1D8, or control MAb SG2G8 bound to Affigel-15 beads (Bio-Rad Laboratories, Richmond, CA), and subjected to SDS-PAGE on 5-20\% gradient gels as previously described (20).

\section{Detection of surface bound MAbs}

Indirect immunofluorescence assessments of the surface binding sites for monoclonal antibodies were performed using saturating concentrations of the monoclonal antibodies and FITC-conjugated goat antimouse IgG (37). Analysis was carried out with a FACScan ${ }^{\star}$ (Becton Dickinson \& Co., Mountain View, CA) flow cytometer. The nonbinding IgG1 MAbs served as control.

An enzyme immunoassay to detect binding of MAbs to monolayers of endothelial cells (canine or human) was performed in 96-well microtiter plates as previously described (20).

Colloidal gold particles $25 \mathrm{~nm}$ in diameter were prepared by citrate reduction and labeled with streptavidin (Zymed Laboratories, San Francisco, CA). Suspensions of canine myocytes which had been fixed for $1 \mathrm{~h}$ in $1 \%$ phosphate-buffered glutaraldehyde were allowed to settle onto poly-L-lysine coated glass cover slips, then rinsed in PBS. Cover slips were treated sequentially with $0.1 \mathrm{M} \mathrm{NH}_{4} \mathrm{Cl}, 1 \% \mathrm{NaIO}_{4}, 0.1 \%$ polyethylene-glycol $20,1 \% \mathrm{BSA}$, and horse serum. They were then incubated for $1 \mathrm{~h}$ at room temperature with $\mathrm{CL1} 18 / 6(50 \mu \mathrm{g} / \mathrm{ml})$, washed in PBS, and incubated for $30 \mathrm{~min}$ with biotinylated horse anti-mouse IgG (Vector Cloning Systems, San Diego, CA). After washing, streptavidin-colloidal gold was applied for $30 \mathrm{~min}$. Controls included omission of primary and secondary antisera. Cover slips were dehydrated in ethanol, critical-point dried using $\mathrm{CO}_{2}$, heavily vacuum coated with carbon, and examined by scanning electron microscopy (JOEL 100CX Temscan). The backscattered electron differential imaging mode was used to demonstrate sites of colloidal gold binding.

\section{Preparation of canine ICAM-1 cDNA by homology} cloning (38)

Isolation of canine spleen RNA and first strand cDNA synthesis. An anesthetized mongrel beagle dog was administered endotoxin (Escherichia coli LPS, Sigma Chemical Co., St. Louis, MO), $(1 \mathrm{mg} / \mathrm{kg} /$ i.v. $)$ for $4 \mathrm{~h}$ before killing and splenectomy. Splenic tissue was immediately frozen in liquid nitrogen and homogenized, and RNA was isolated by an acid-guanidinium-phenol chloroform procedure (39). A 30- $\mu \mathrm{g}$ aliquot of RNA was primed with $4 \mu \mathrm{g}$ oligo(dT) $)_{12-18}$ (Pharmacia LKB Biotechnology, Inc., Piscataway, NJ) at $55^{\circ} \mathrm{C}$ in a total vol of $24 \mu \mathrm{l}$ for 3 $\mathrm{min}$, and first strand cDNA was then synthesized in a final vol of $40 \mu \mathrm{l}$ containing the following: $36 \mathrm{U}$ of avian myeloblastosis virus reverse transcriptase (Life Sciences, St. Petersburg, FL), $1.4 \mathrm{U}$ of placental RNAsin (Promega Biotec, Madison, WI), $1 \mathrm{mM}$ each dNTP, $10 \mathrm{mM}$ dithiothrietol, and $0.1 \mathrm{M}$ Tris $\mathrm{HCl}(\mathrm{pH}$ 7.5). The reaction was incubated for $45 \mathrm{~min}$ at $42^{\circ} \mathrm{C}$ and an additional $36 \mathrm{U}$ of reverse transcriptase was added for an additional $45 \mathrm{~min}$.

Amplification and cloning of canine cDNA for ICAM-1. Degenerate oligonucleotide primer mixtures were selected to correspond to highly conserved sequences of murine and human ICAM-1 cDNA $(40,41)$ (see Fig. 4). These included sense and antisense primer mixtures corresponding to the murine ICAM-1 cDNA sequences 575-591 (within Ig domain 2) and 1286-1302 (within Ig domain 5), respectively. BamHI linker sequences were added to the corresponding 5 ' terminus of each primer.

Canine spleen cDNA was amplified using the polymerase chain reaction (PCR) (42) with the primer mixtures indicated above. PCR was performed in a total vol of $50 \mu \mathrm{l}$ containing the following: $10 \mathrm{mM}$ Tris- $\mathrm{HCl}$ (pH 8.3), $2 \mathrm{mM} \mathrm{MgCl} 2,50 \mathrm{mM} \mathrm{KCl}, 0.01 \%$ gelatin, $0.4 \mathrm{mM}$ each dNTP, $20 \mu \mathrm{M}$ each primer mixture, 20-40 ng canine cDNA, and $1 \mathrm{U}$ of Amplitaq polymerase (Perkin-Elmer Cetus, Norwalk, CT). Amplification was performed for 30 cycles with denaturation for $1 \mathrm{~min}$ at $94^{\circ} \mathrm{C}$, annealing for $2 \mathrm{~min}$ at $48^{\circ} \mathrm{C}$, and extension for $4 \mathrm{~min}$ at $72^{\circ} \mathrm{C}$.

Aliquots of PCR reactions were analyzed on $1 \%$ agarose gels followed by Southern blotting using nitrocellulose membranes (43) and hybridization with human or murine cDNA probes for ICAM-1 labeled by the random hexamer method (44). A product of $740 \mathrm{bp}$ was observed by ethidium staining and by hybridization for both the canine and murine PCR products. The canine PCR product was digested with BamH1 and cloned into M13mp18 (45). Single stranded DNA template was sequenced using the dideoxy chain termination method (U.S. Biochemical Corp., Cleveland, $\mathrm{OH}$ ) (46).

\section{Northern blot analysis}

RNA was isolated from cultured canine jugular vein endothelial cells (CJVEC) or canine myocytes using the acid-guanidinium-phenol chloroform procedure (39). RNA (10-20 $\mu \mathrm{g})$ was electrophoresed on $1 \%$ agarose gel containing $1 \%$ formaldehyde and then transferred to a nytran membrane (Gene Screen Plus; New England Nuclear, Boston, MA) by standard procedures (43). The membranes were hybridized in $50 \%$ formamide, $10 \%$ dextran sulfate, $1 \%$ SDS, $96 \mathrm{mM} \mathrm{NaCl}, 0.15$ $\mathrm{mg} / \mathrm{ml}$ salmon sperm DNA, and $4 \times 10^{6} \mathrm{cpm}$ of random hexamer labeled canine probe. Filters were washed with $2 \times \mathrm{SSC}$ at $21^{\circ} \mathrm{C}$ for 5 min twice and with $2 \times \mathrm{SSC}$ with $1 \% \mathrm{SDS}$ at $65^{\circ} \mathrm{C}$ for 30 min twice and were then exposed to Kodak XLR film.

\section{Canine neutrophil adherence to canine endothelial monolayers}

CJVEC were obtained by a modification of the method of Ford (47) as previously described (32). Cover slips with attached endothelial monolayers were inserted in adhesion chambers, and adherence of isolated canine neutrophils was determined in the absence of shear stress using a visual assay as previously described $(20,22)$. In experiments with stimulated endothelial cells, monolayers were exposed to cytokines for $3 \mathrm{~h}$ at $37^{\circ} \mathrm{C}$, then rinsed by dipping the cover slip five times in two changes of PBS before being inserted into the adherence chambers. In experiments with monoclonal antibodies, neutrophils were exposed to 

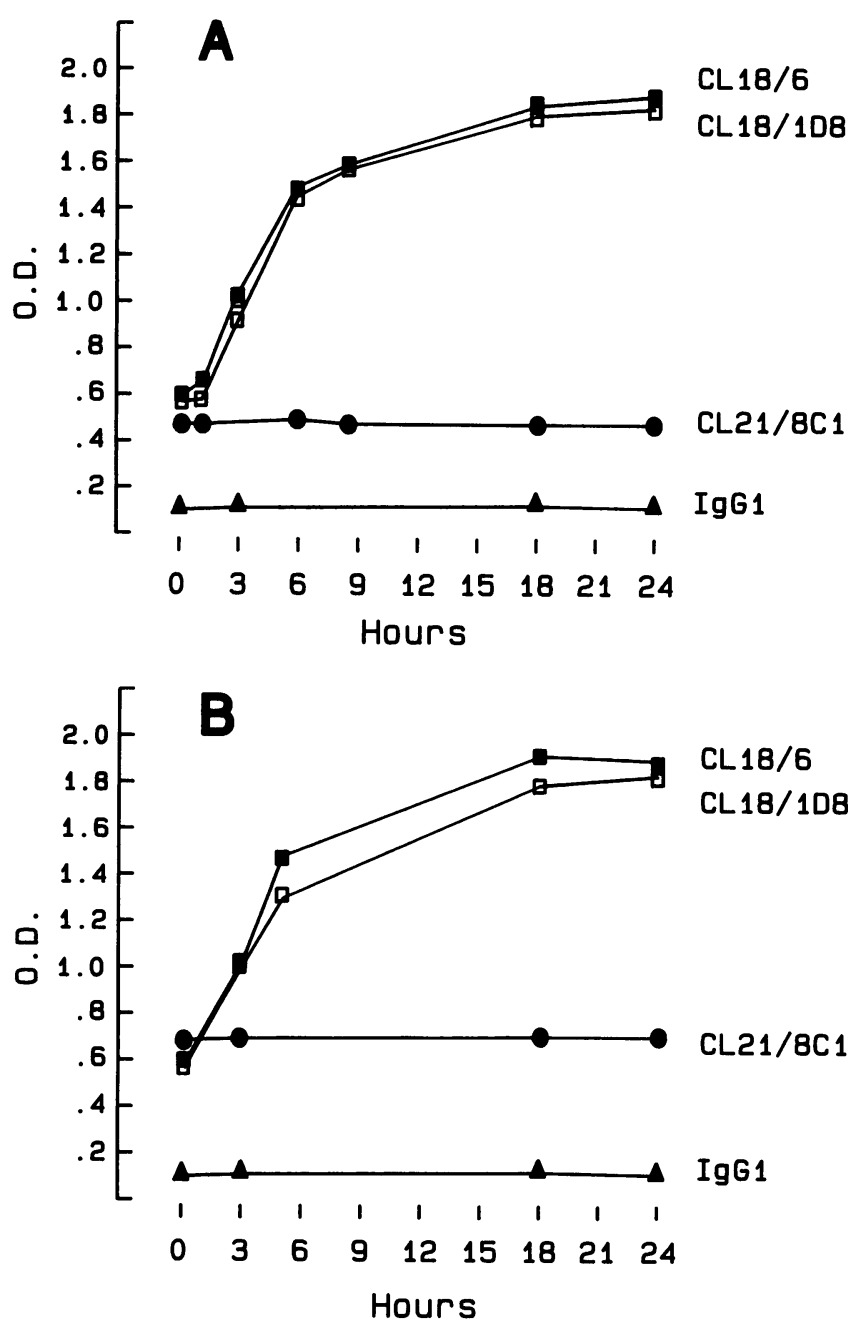

Figure 1. Changes in canine endothelial cell surface antigens after LPS and rTNF $\alpha$ stimulation. CJVEC monolayers were prepared in 96-well microtiter plates, stimulated with either $(A)$ LPS $(10 \mathrm{ng} / \mathrm{ml})$ or $(B)$ $\mathrm{rTNF} \alpha(30 \mathrm{U} / \mathrm{ml})$ for the times indicated, washed in PBS, and exposed to antiendothelial MAbs CL18/6, CL18/1D8, or CL21/8C1, or a nonbinding isotyped-matched control. Antibody binding was detected using alkaline phosphatase bound anti-mouse IgG. These results are representative of three separate experiments.

the antibodies at room temperature for $5 \mathrm{~min}$ before the cell suspension containing the antibodies was injected into the adherence chambers.

\section{Canine neutrophil-myocyte adherence}

Isolated canine myocytes were suspended at a concentration of 50,000 / $\mathrm{ml}$. Neutrophils and myocytes were coincubated in a volume of $0.4 \mathrm{ml}$ at a ratio of $10: 1$, neutrophils:myocytes, for $30 \mathrm{~min}$ at $37^{\circ} \mathrm{C}$. The cells were resuspended, a small aliquot transferred to a microscope slide, covered with a cover glass, and cells were examined under phase contrast or differential interference contrast optics. The percentage of myocytes with $>2$ attached neutrophils was determined and the number of neutrophils per myocyte was counted on 200 myocytes per preparation. Samples were coded so that data collection was performed without knowledge of the specific experimental conditions. In experiments with stimulated myocytes, myocytes were incubated with recombinant interleukin-1 (rIL-1 $\beta$; Genzyme Corp., Cambridge, MA), recombinant tumor necrosis factor (rTNF $\alpha$ ), or LPS for various times at $37^{\circ} \mathrm{C}$, before addition of the neutrophils. In experiments with stimulated neutro- phils, platelet activating factor (PAF) or zymosan activated canine serum (ZAS) (6) was added immediately before the neutrophil suspension was mixed with the suspension of myocytes. Monoclonal antibodies were added to the neutrophil-myocyte suspension at the beginning and remained with the cells throughout the incubation period.

\section{Data presentation}

Results are presented as means $\pm 1 \mathrm{SD}$, and $n=$ the number of separate experiments. Statistical assessments were made using analysis of variance and Dunnett's $t$ test or Student's $t$ test.

\section{Results}

Development of anti-canine ICAM-1 MAbs. To evaluate the role of ICAM-1 in canine neutrophil adherence to endothelial cells and cardiac myocytes, MAbs against canine ICAM-1 were needed. Since a currently available MAb against human ICAM-1 (R6.5) previously shown to inhibit human neutrophil adhesion $(20,22,36)$ did not cross-react with canine ICAM-1, it was necessary to characterize new MAbs as reagents that would block the neutrophil related functions of ICAM-1. This was carried out by evaluating canine neutrophil adhesion to canine endothelial monolayers.

Two MAbs were chosen for the studies of the canine model because they exhibited the characteristics previously seen with anti-ICAM-1 in studies of human cells. CL18/6 and CL18/ 1D8 bound to unstimulated CJVEC, and binding was increased by exposure of the endothelial cells to LPS $(10 \mathrm{ng} / \mathrm{ml})$ or rTNF $\alpha(30 \mathrm{U} / \mathrm{ml})$ over a time course consistent with the upregulation of ICAM-1 on human endothelium $(22,48)$ (Fig. 1). The binding of another anti-endothelial cell MAb (CL21/ $8 \mathrm{C} 1$ ) did not change over the observation period. Immunoprecipitation studies of ${ }^{125}$ I surface labeled CJVEC revealed that the endothelial antigen recognized by both CL18/6 and CL18/ $1 \mathrm{D} 8$ was $95 \mathrm{kD}$ (Fig. 2), and CL18/6 removed the antigen recognized by CL18/1D8; CL18/1D8 also greatly reduced the antigen from cell lysates recognized by CL18/6 (Fig. 2). Flow cytometry studies revealed that when compared with a nonbinding IgG1 control, neither CL18/6 nor CL18/1D8 bound to

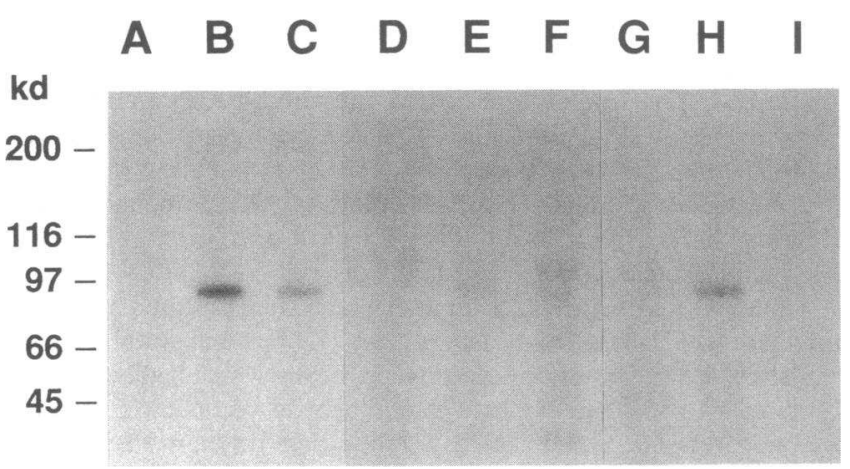

Figure 2. Immunoprecipitation study of the CL18/6 and CL18/1D8 antigens on canine endothelial cells. CJVEC were surface labeled with ${ }^{125}$ I. NP-40 lysates were immunoprecipitated using either MAb SG8 (an antineutrophil MAb that does not bind to endothelial cells) (lane $A$ ), CL18/6 (lane $B$ ), or CL18/1D8 (lane $C$ ). Cell lysates were also pretreated with CL18/6 Affigel-15 beads, and then immunoprecipitated with SG2G8 (lane D), CL18/6 (lane $E$ ), or CL18/1D8 (lane $F$ ). Additionally, cell lysates were pretreated with CL18/1D8 Affigel-15 beads, and then immunoprecipitated with SG2G8 (lane G), CL18/6 (lane $H$ ), or CL18/1D8 (lane $I$ ). 
canine neutrophils, and using an enzyme immunoassay, these MAbs did not bind to human endothelial cell monolayers.

Previous studies have shown that canine neutrophil adherence to canine endothelial cell monolayers resembles that of human cells in that it is markedly enhanced by stimulation of the endothelial cells with LPS, and partially CD18-dependent as shown by studies using the anti-CD18 MAb R15.7 $(26,32)$. Dose response increases in neutrophil adhesion to endothelial cells stimulated with LPS and rTNF $\alpha$ were seen below $10 \mathrm{ng} /$ $\mathrm{ml}$ for LPS, and $10 \mathrm{U} / \mathrm{ml}$ with $\mathrm{rTNF} \alpha$. Time course studies revealed that with both stimuli, peak adhesion was evident after $4 \mathrm{~h}$ of stimulation, fell to about $50 \%$ of peak levels by $8 \mathrm{~h}$, and remained at that level for $24 \mathrm{~h}$. Direct comparisons of the inhibitory effects of anti-CD18 (R15.7) and CL18/6 were made using CJVEC stimulated with LPS at optimum concentrations for $4 \mathrm{~h}$ (to obtain peak adherence), or LPS for $8 \mathrm{~h}$ (a time interval previously shown with human endothelial cells to be largely CD18-dependent adhesion [20, 22]). As shown in Fig. 3, the extent of inhibition induced by each MAb was the same,

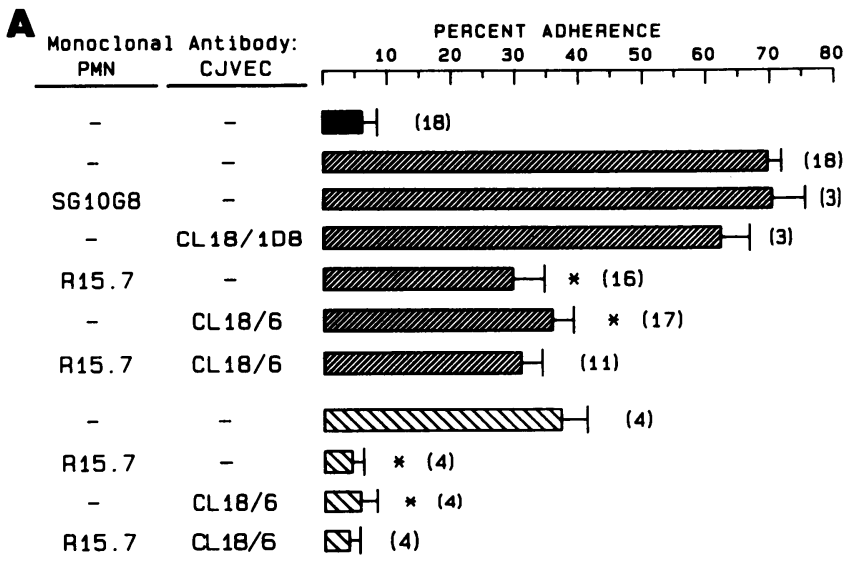

$\mathbf{B}$

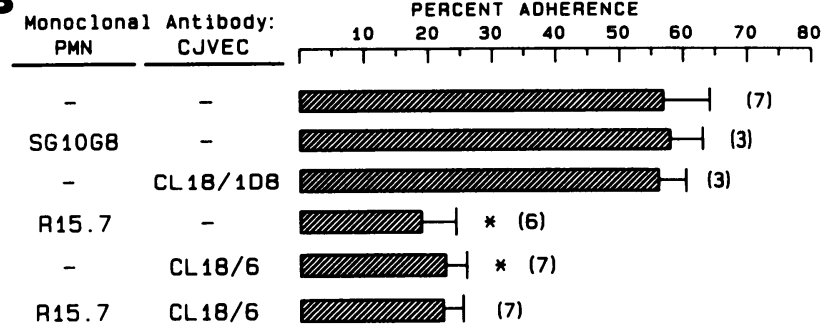

Figure 3. Effects of MAbs on neutrophil adhesion to endothelial cells. Monolayers of CJVEC were exposed to $(A) \operatorname{LPS}(10 \mathrm{ng} / \mathrm{ml}$ for $4 \mathrm{~h}$, fine cross-hatched bars, or $8 \mathrm{~h}$, coarse cross-hatched bars) or $(B)$ $\mathrm{rTNF} \alpha(30 \mathrm{U} / \mathrm{ml}$ for $4 \mathrm{~h})$, washed, and placed in adhesion chambers. Neutrophil adhesion was determined visually after a contact time of $500 \mathrm{~s}$ and a detachment time at unit gravity of $500 \mathrm{~s}$. Neutrophils were exposed to the indicated MAbs $(10 \mu \mathrm{g} / \mathrm{ml})$ immediately before their introduction into and throughout their time in the adhesion chamber, and CJVEC monolayers were exposed to the indicated MAbs $(10 \mu \mathrm{g} / \mathrm{ml})$ for $25 \mathrm{~min}$ before being placed in the adhesion chamber, and additional antibody was not provided during the adhesion assay. The solid bar indicates the adhesion of unstimulated neutrophils to control unstimulated endothelial cells. The number in parentheses indicates the number of separate experiments; ${ }^{*} P<0.01$ compared to the stimulated endothelial cells without MAbs. and there was no increase in the inhibition when both were added during the adhesion assay. Additionally, CL18/6 was equivalent to the anti-CD18 MAb in blocking adhesion to the 8 h LPS stimulated CJVEC. Control isotype-matched MAbs SG10G8 (anti-canine neutrophil, antigen unknown) and CL18/1D8 did not significantly influence adhesion (Fig. 3). Thus, while CL18/6 appears to recognize a functional epitope, CL18/1D8 does not.

In contrast to human endothelial cells (22), CJVEC did not appear to respond to human rIL-1 $\beta$. Over a wide concentration range (1-100 U/ml), rIL-1 $\beta$ did not induce increases in adhesion of canine neutrophils or increases in the binding of CL18/ 6 at observation times of 4 or $8 \mathrm{~h}$.

Regulation of canine ICAM-1 mRNA. A partial cDNA clone for canine ICAM-1 was isolated using the polymerase chain reaction for homology cloning. The nucleotide sequence of the primer mixtures used for amplification and the amino acid sequence of the cloned segment are presented in Fig. 4, $A$ and $B$. Substantial homology to the sequences for human and murine ICAM-1 were present with amino acid identity of $60.9 \%$ between human and canine and $53.5 \%$ identity between canine and murine sequence. The nucleotide identity for the available region was $73.8 \%$ between canine and human and $61.2 \%$ between canine and murine. The nucleotide sequence of this partial cDNA is available in Genbank (accession \#M68524).

Northern blot analysis using the partial canine ICAM-1 cDNA revealed that LPS and rTNF $\alpha$, but not rIL- $1 \beta$, stimulated increased production of ICAM-1 mRNA in CJVEC (Fig. $5)$. This was consistent with the differential effects of these mediators on both cell surface levels of ICAM-1, and ICAM-1-dependent adhesion of neutrophils (above). As demonstrated, a $>10$-fold increase of total cell ICAM-1 mRNA was evident in CJVEC preincubated with LPS for $3 \mathrm{~h}$ before isolation of RNA. In addition to the dominant hybridizing band of $2.9 \mathrm{~kb}$, a lower molecular weight band of $\sim 1.9 \mathrm{~kb}$ was consistently evident in analyses of stimulated but not unstimulated CJVEC. Studies of the kinetics of induction of total CJVEC ICAM-1 mRNA by LPS revealed marked increases in ICAM-1 mRNA within 0.5$1 \mathrm{~h}$ and peak levels after 5-7 $\mathrm{h}$ of LPS stimulation. Following longer time intervals (18-24 h), CJVEC ICAM-1 mRNA levels were decreased though endothelial cell surface ICAM-1 remained high (Fig. 1).

Effect of MAb CL18/6 on neutrophil adhesion to canine cardiac myocytes. Previous studies have shown that chemotactically stimulated canine neutrophils adhere to canine cardiac myocytes stimulated for $3 \mathrm{~h}$ with rIL-1 $\beta, \mathrm{rTNF} \alpha$ (32), or LPS (unpublished data). To determine whether the antigen recognized by CL18/6 is involved in this adhesion, stimulated myocytes were incubated with CL18/6. This MAb bound extensively to myocytes $3 \mathrm{~h}$ after stimulation with $\mathrm{rIL}-1 \beta(10 \mathrm{U} / \mathrm{ml})$ (Fig. 6). As was the case with R15.7, CL18/6 almost completely inhibited the adhesion of chemotactically stimulated neutrophils to rIL-1 $\beta$ stimulated cardiac myocytes (Fig. 7), but as was found with endothelial-neutrophil adhesion, CL18/1D8 did not inhibit neutrophil adhesion. Additional studies using myocytes stimulated with $\mathrm{rTNF} \alpha(100 \mathrm{U} / \mathrm{ml})$ revealed the same inhibitory effects of MAbs CL18/6 and R15.7, and the extent of inhibition was $>90 \%(n=5, P<0.01)$.

Regulation of canine myocyte ICAM-1 $m R N A$. Northern blot analyses of total cell mRNA from isolated canine myocytes showed a single 2.9-kb hybridizing band (Fig. 8). As illus- 
A. SENSE OLIGONUCLEOTIDE MIXTURE

$5^{\prime}$

CGTAGGATCCAATTTCTCGTGTCGGAC

$\begin{array}{lllll}\mathbf{A} & \mathbf{T} & \mathbf{A} & \mathbf{C} & \mathbf{A}\end{array}$

T $\quad$ T

ANTISENSE OLIGONUCLEOTIDE MIXTURE

GTGAGGATCCTTGCCCAGGCCTGGCA
$\begin{array}{llll}\text { A } & \text { A } & \text { T } & \text { A } \\ \text { T } & \text { T } & & \\ \text { C } & \text { C } & \end{array}$

B. COMPARISON OB AMINO ACID SEQUENCES

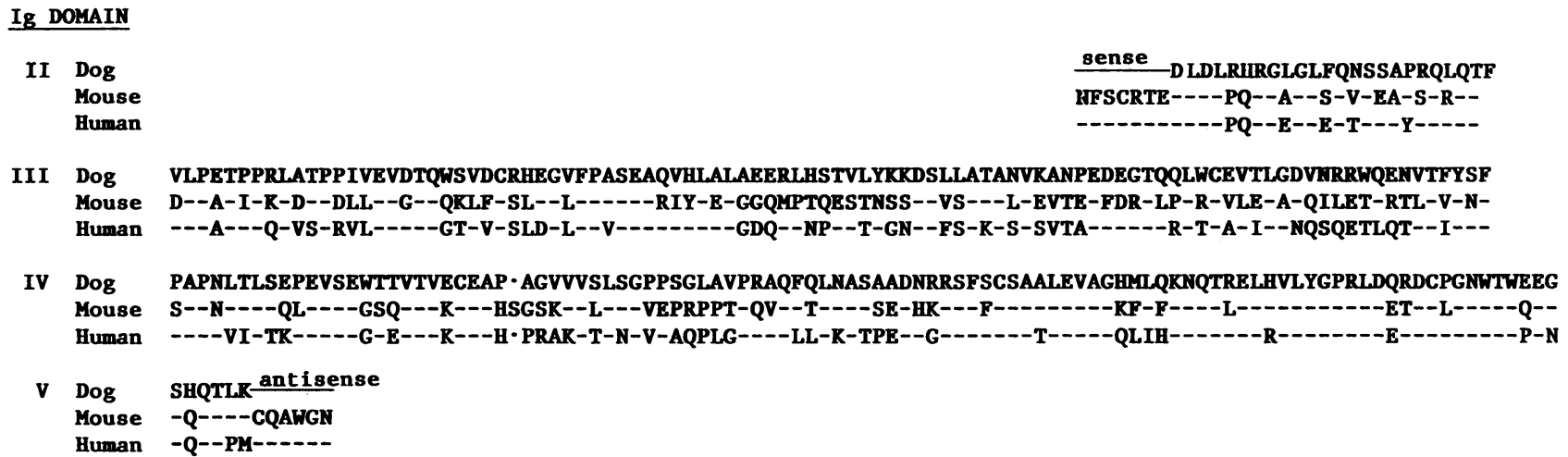

Figure 4. Comparison of canine, murine, and human ICAM-1. A partial canine ICAM-1 cDNA was prepared by PCR amplification, cloned into M13mp18, and sequenced. Sense and antisense oligonucleotide primer mixtures $(A)$ were prepared based on conserved sequences observed among human and murine ICAM-1 within Ig domain II and V. Underlined sequences indicate BamHI restriction sites. The deduced amino acid sequences inclusive of the canine ICAM-1 CDNA PCR product are compared to those of murine and human ICAM-1 (B).

trated in Fig. $8 A$, rIL- $1 \beta$, rTNF $\alpha$, and LPS were equally stimulatory of ICAM-1 mRNA, findings concordant with the known effects of these stimuli on ICAM-1-dependent myocyte adhesion to chemotactically stimulated neutrophils (32). Levels of ICAM-1 mRNA were very low or undetectable in unstimulated myocytes, and increases after LPS or cytokine stimulation were less than those observed in CJVEC (Fig. 8 B) (i.e., approximately twofold increase as compared to a greater than 10-fold increase for LPS stimulated CJVEC as shown in Fig. 5 B).

\section{Discussion}

The evidence supporting the conclusion that MAbs CL18/6 and CL18/1D8 recognized the canine homologue of ICAM-1 is as follows: ( $a$ ) They bound to a constitutively expressed antigen on canine endothelial cells. This surface antigen exhibited a marked increase by $3 \mathrm{~h}$ that was sustained up to $24 \mathrm{~h}$ after stimulation of the endothelial cells with rTNF $\alpha$ and LPS. This pattern is consistent with ICAM-1 expression on human umbilical vein endothelial cells $(22,48)$. (b) They recognized the same surface antigen of $95 \mathrm{kD}$, a size consistent with human ICAM-1 (33). (c) The specific adhesive events that were inhibited by CL18/6 were entirely consistent with the functions of ICAM-1 in human neutrophil/endothelial interactions in vitro (21). These functions were each CD18-dependent as shown by the findings that MAb R15.7 inhibited the same events, and combining CL18/6 and R15.7 did not result in greater inhibition than with either MAb alone. (d) ICAM-1 mRNA levels were markedly increased in CJVEC after rTNF $\alpha$ and LPS stimulation over a time frame similar to that of human umbilical vein endothelial cells, and under conditions associated with CL18/6 antigen on the cell surface and CL18/6-inhibitable neutrophil adhesion. The definitive experiment showing that the MAbs react with the cloned gene product has not been performed because we have not yet obtained a full length cDNA clone. Nonetheless, the observations to date are consistent with the conclusion that canine endothelial ICAM-1 functions as an adhesion molecule for canine neutrophils.

The results in this report indicate that canine cardiac myocytes also synthesize and express on their surface ICAM-1, and that this ICAM-1 also functions as an adhesive molecule for neutrophils. As we previously reported (32), the upregulation of myocyte adhesiveness requires protein synthesis, and results of the present studies do not indicate that there is constitutive expression of ICAM-1 by myocytes. However, when myocytes were exposed to rIL- $1 \beta$, rTNF $\alpha$ or LPS, CL18/6 binding and ICAM-1 mRNA were detected, neutrophil adhesion was signifcantly increased, and this adhesion was almost entirely inhibitable by either CL18/6 or R15.7. In contrast to the results with endothelial cells $(24,36)$, chemotactically stimulated neutrophils do not show significant ICAM-1-independent adhesion to cardiac myocytes. This is evident in two types of experiments. PAF or ZAS stimulated neutrophils do not adhere to unstimulated myocytes (32), and adhesion of neutrophils to cytokinestimulated myocytes is inhibited by $>90 \%$ (Fig. 7). Recent evidence indicates that ICAM-1 can serve as a ligand for CD1 1b/CD18 (Mac-1) $(22,36)$ as well as CD1 1a/CD18 (LFA- 

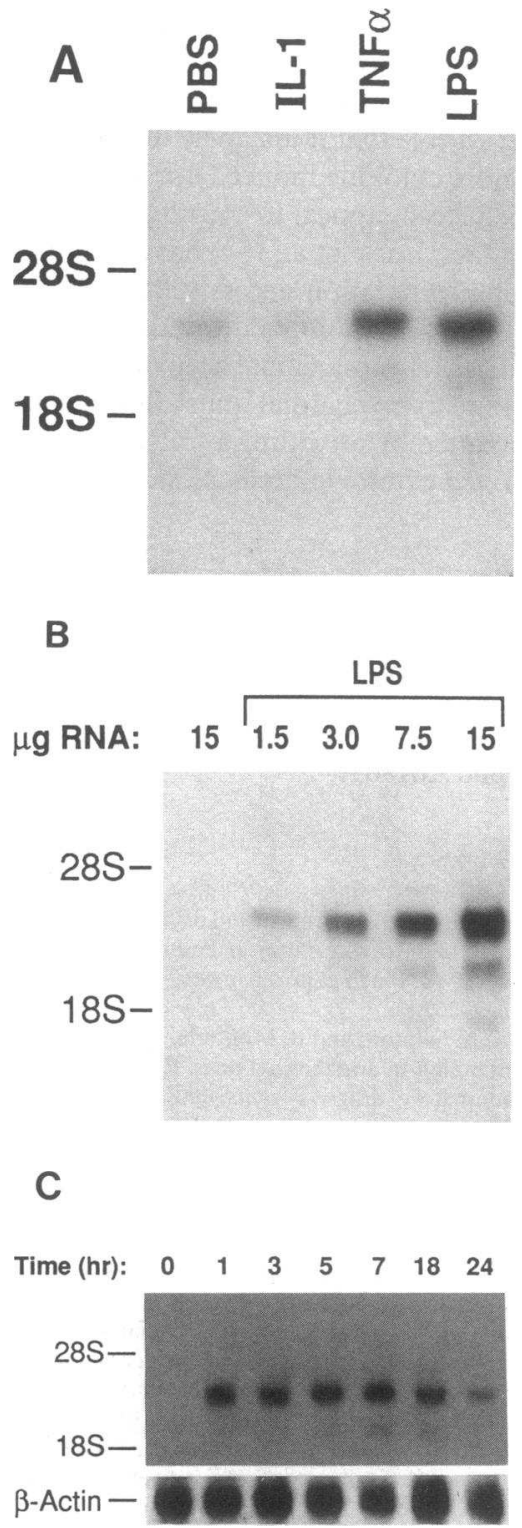

Figure 5. Regulation of CJVEC ICAM-1 mRNA by LPS, rTNF $\alpha$, or rIL-1 $\beta$. Total cell RNA was isolated from T175 flasks of CJVEC preincubated in the presence or absence of LPS $(10 \mathrm{ng} / \mathrm{ml}), \mathrm{rIL}-1 \beta$ $(10 \mathrm{U} / \mathrm{ml})$, or rTNF $\alpha$ (30 U/ml) for varying time intervals, and Northern blots of RNA aliquots were hybridized with a $740-b p{ }^{32}$ P-labeled canine ICAM-1 cDNA as described in Methods. Differential stimulatory effects of rIL- $1 \beta$ as compared to rTNF $\alpha$ or LPS $(3.5 \mathrm{~h}$, $37^{\circ} \mathrm{C}$ ) are shown $(A)$. The effects of LPS on quantitative levels of ICAM-1 mRNA are shown in $(B)$ where 1.5 ng-15 ng of RNA from stimulated CJVEC or 15 ng of RNA from unstimulated CJVEC are loaded and compared. The time course of CJVEC canine ICAM-1 mRNA regulation in response to LPS incubation is shown in $(C)$. For these experiments, a ${ }^{32} \mathrm{P}$-avian $\beta$-actin cDNA was used to rehybridize stripped membranes to demonstrate equivalent levels of RNA in each lane.

1) $(34,35)$, though on endothelial cells there is evidence that Mac-1 can bind to some moiety in addition to ICAM-1 $(24,36)$

It is reasonable to propose that neutrophil adherence to endothelial cells and cardiac myocytes is of pathogenic signifcance in reperfusion injury. Numerous studies have demonstrated a significant reduction in infarct size in animal models of cardiac ischemia and reperfusion after manipulations that either remove circulating neutrophils during the periods of ischemia and/or reperfusion (1) (e.g., administration of antineutrophil antisera, or the use of filters to remove neutrophils from the blood), or that possibly alter the inflammatory functions of neutrophils (e.g., administration of antiinflammatory drugs known to reduce neutrophil accumulation). Such studies generally support a role for neutrophils in myocardial damage. The specific mechanisms by which these cells localize in the tissue, or how they may damage the myocytes, are still unknown. However, recent results indicate possibly important roles for adhesion molecules. The use of MAbs against CD18 appears to

reduce accumulation of neutrophils in both rabbit and canine models (12, 13, 15, 17-19). Additionally, the systemic administration of an anti-CD11b MAb significantly reduced infarct size in a canine model $(14,16)$. These observations are consistent with the experiments using other models of injury after ischemia and reperfusion at extracardiac sites showing a significant CD18-dependent component $(49,50)$. Evidence that ICAM-1 may play a role in postischemic inflammatory cardiac injury was provided by studies using MAb R6.5, an antiICAM-1 that appears to cross-react with rabbit ICAM-1 (12). This MAb reduced infarct size in a rabbit model by $50 \%$. Moreover, recent studies using the canine ICAM-1 cDNA probe described herein have demonstrated detectable levels of ICAM-1 mRNA in ischemic but not normal segments of ca-
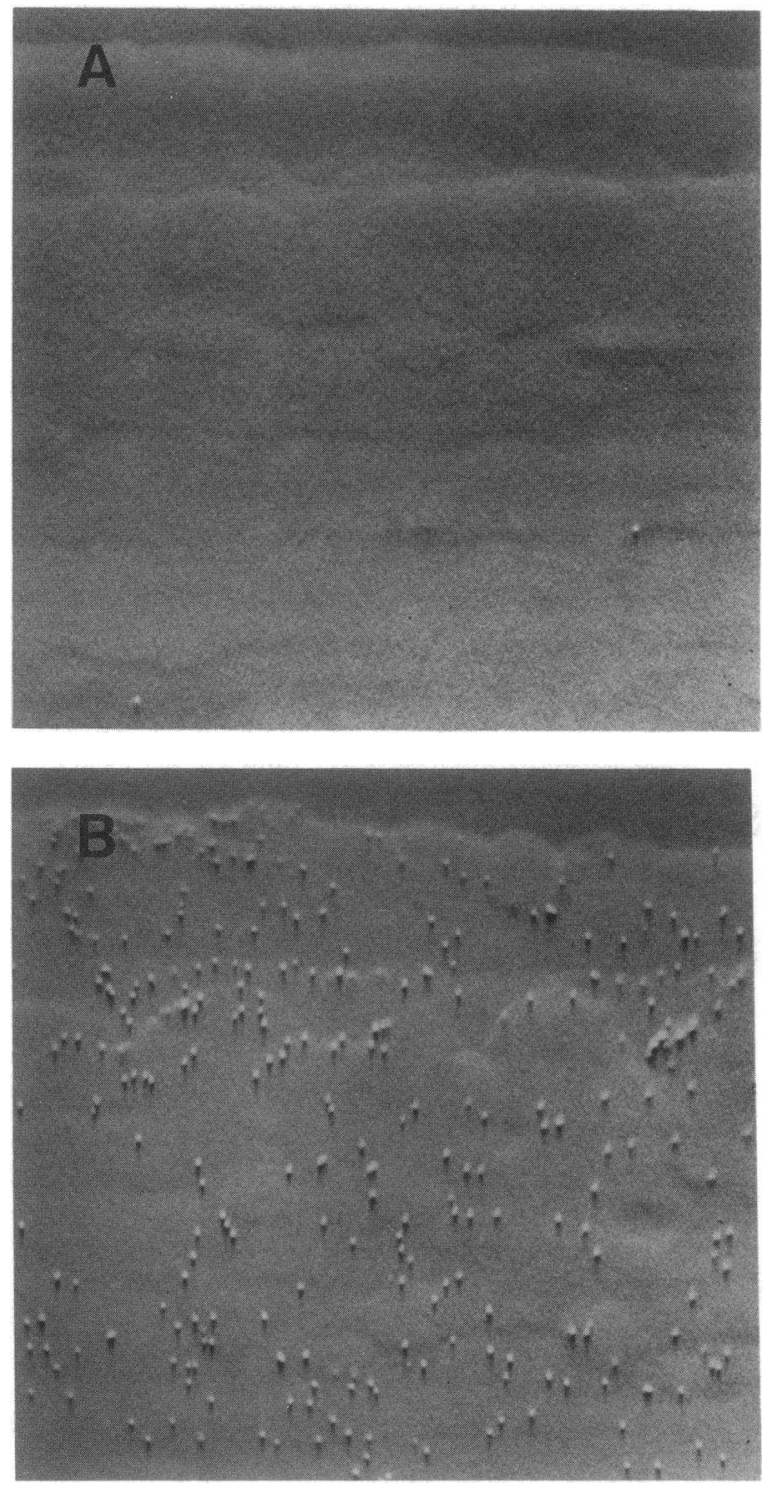

Figure 6. Colloidal gold labeling of CL18/6 binding sites on IL-1-stimulated cardiac myocytes. Cells were incubated with CL18/6, biotinylated anti-mouse IgG, and streptavidin-labeled colloidal gold. $(A)$ Control omitting CL18/6, showing low level of nonspecific binding of colloidal gold. $(B)$ Representative cell incubated with CL18/6 showing extensive binding of $25 \mathrm{~nm}$ colloidal gold particles. Backscattered electron imaging, magnification $\sim 30,000$. 


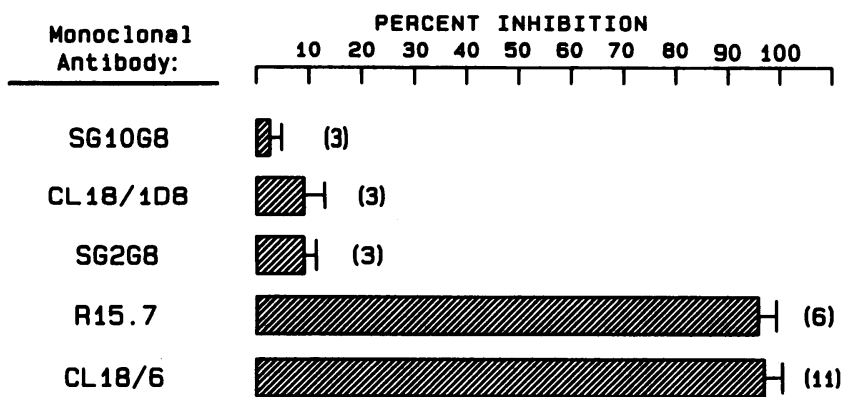

Figure 7. Effects of MAbs on neutrophil adhesion to cardiac myocytes stimulated with rIL-1 $\beta$. Isolated canine cardiac myocytes were incubated for $3 \mathrm{~h}$ with $4 \mathrm{U} / \mathrm{ml} \mathrm{rIL-1} \beta$, then exposed to canine neutrophils in the presence of $1 \%$ ZAS with and without the MAbs indicated (50 $\mu \mathrm{g} / \mathrm{ml}$ ). The percent inhibition of adhesion was calculated for each experiment and the mean \pm 1 SD plotted. The number in parentheses indicates the number of separate experiments. The values for MAbs R15.7 and CL18/6 are significant $(P<0.01)$. MAbs SG10G8, SG2G8, and R15.7 (anti-CD18) all bind to neutrophils but not myocytes. MAbs CL18/1D8 and CL18/6 bind to canine myocytes but not neutrophils.

nine myocardium after experimental coronary artery occlusion $(1 \mathrm{~h})$ and reperfusion $(3 \mathrm{~h})$ (Anderson, D. C., and $\mathrm{M}$. Entman, unpublished observations). Thus, a possible mechanism contributing to neutrophil mediated myocyte damage
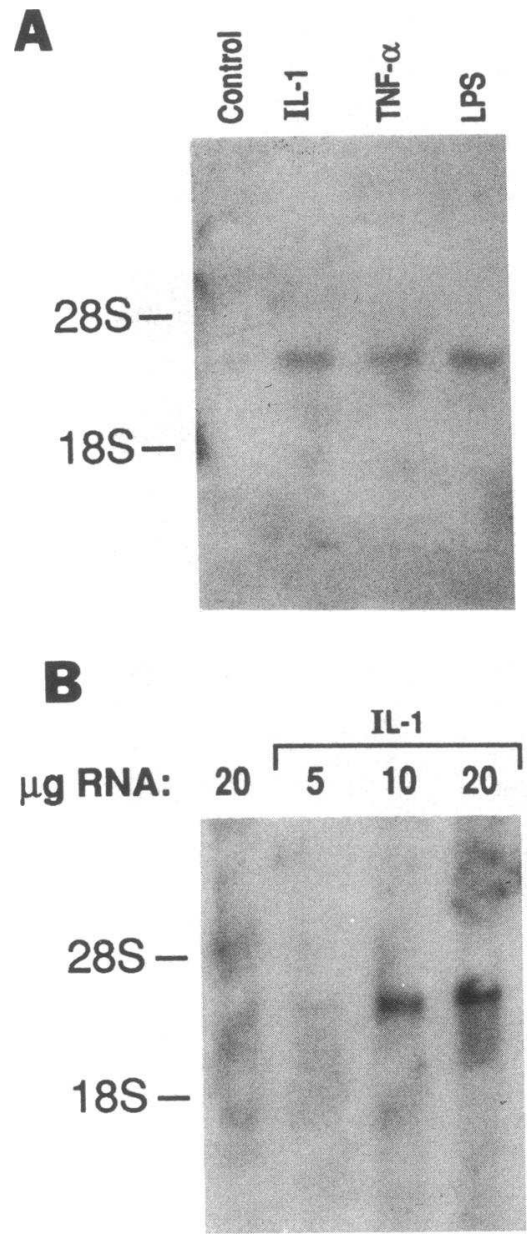

Figure 8. Regulation of canine myocyte ICAM1 mRNA by LPS or cytokines. Total cell RNA was isolated from isolated canine myocytes preincubated in the presence or absence of LPS $(10 \mathrm{ng} / \mathrm{ml})$, rIL- $1 \beta$ $(10 \mathrm{U} / \mathrm{ml})$, or rTNF $\alpha$ $(30 \mathrm{U} / \mathrm{ml})$ for $3 \mathrm{~h}$ at $37^{\circ} \mathrm{C}$, and Northern blots of RNA aliquots were hybridized with a 740-bp ${ }^{32}$ P-labeled canine ICAM-1 cDNA prepared as described in Methods $(A)$. Hybridizing signals $(\sim 2.9 \mathrm{~kb})$ are demonstrated for blots of $15 \mu \mathrm{g}$ of RNA of IL- $1 \beta$, TNF $\alpha$, and LPS stimulated but not unstimulated myocytes (B). rIL-1 $\beta$ elicits a greater than twofold increase of this hybridizing signal as shown in comparative blots of varying quantities of RNA. may result from local cytokine stimulation of endothelial or myocyte ICAM-1 expression. Endothelial ICAM-1 could contribute to neutrophil localization through its role in transendothelial migration $(20,22)$, a role that it may play in the early phases of inflammation before cytokine induced upregulation, since postcapillary endothelial cells appear to constitutively express ICAM-1 $(33,51)$. In fact, Furie et al. (52) have recently demonstrated that neutrophil migration across unstimulated endothelial cells in vitro toward a chemotactic gradient is reduced by $\sim 50 \%$ by anti-ICAM-1 monoclonal antibody. Myocyte ICAM- 1 could contribute to myocardial injury through its role in neutrophil adhesion, thereby providing a small distance over which neutrophil-derived cytotoxic molecules could act.

\section{Acknowledgments}

The expert technical assistance of B. J. Hughes and Sharon Krater is acknowledged, as well as the expert secretarial assistance of Irene Harrison and Michelle Swarthout.

This research was supported in part by National Institutes of Health grants HL-42550, HL-41408 and AI-19031.

\section{References}

1. Mullane, K. M., and C. W. Smith. 1990. The role of leukocytes in ischemic damage, reperfusion injury and repair of the myocardium. In Pathophysiology of Severe Ischemic Myocardial Injury. H. M. Piper, editor. Kluwer Academic Publishers, Dordrecht, Netherlands. 239-267.

2. Mullane, K. M., N. Read, J. A. Salmon, and S. Moncada. 1984. Role of leukocytes in acute myocardial infarction in anesthetized dogs. Relationship to myocardial salvage by anti-inflammatory drugs. J. Pharmacol. Exp. Ther. 228:510-522.

3. Engler, R. L., M. D. Dahlgren, M. A. Peterson, A. Dobbs, and G. W. Schmid-Schonbein. 1986. Accumulation of polymorphonuclear leukocytes during 3h experimental myocardial ischemia. Am. J. Physiol. 251:H93-100.

4. Schmid-Schoenbein, G. W., and R. L. Engler. 1987. Granulocytes as active participants in acute myocardial ischemia and infarction. Am. J. Cardiovasc. Pathol. 1:15-30.

5. Rossen, R. D., J. L. Swain, L. H. Michael, S. Weakley, E. Giannini, and M. L. Entman. 1985. Selective accumulation of the first component of complement and leukocytes in ischemic canine heart muscle: a possible initiator of an extra myocardial mechanism of ischemic injury. Circ. Res. 57:119-130.

6. Dreyer, W. J., C. W. Smith, L. H. Michael, R. D. Rossen, B. J. Hughes, M. L. Entman, and D. C. Anderson. 1989. Canine neutrophil activation by cardiac lymph obtained during reperfusion of ischemic myocardium. Circ. Res. 65:1751-1762.

7. Engler, R. L., M. D. Dahlgren, D. D. Morris, M. A. Peterson, and G. W. Schmid-Schonbein. 1986. Role of leukocytes in response to acute myocardial ischemia and reflow in dogs. Am. J. Physiol. 251:H314-323.

8. Romson, J. L., B. G. Hook, S. L. Kunkel, G. D. Abrams, M. A. Schork, and B. R. Lucchesi. 1983. Reduction of the extent of ischemic myocardial injury by neutrophil depletion in the dog. Circulation. 67:1016-1023.

9. Jolly, S. R., W. J. Kane, B. G. Hook, G. D. Abrams, S. L. Kunkel, and B. R. Lucchesi. 1986. Reduction of myocardial infarct size by neutrophil depletion: effect of duration of occlusion. Am. Heart J. 112:682-690.

10. DeLorgeil, M., A. Basmadjian, M. Lavalle, R. Clement, D. Millette, G. Rousseau, and J. G. Latour. 1989. Influence of leukopenia on collateral flow, reperfusion flow, reflow ventricular fibrillation, and infarct size in dogs. $\mathrm{Am}$. Heart J. 117:523-532.

11. Harlan, J. M. 1990. Consequences of leukocyte-vessel wall interactions in inflammatory and immune reactions. Semin. Thromb. Hemostasis. 13:434-444.

12. Seewaldt-Becker, E., R. Rothlein, and J. W. Dammgen. 1989. CDw18 dependent adhesion of leukocytes to endothelium and its relevance for cardiac reperfusion. In Leukocyte Adhesion Molecules: Structure, Function, and Regulation. T. A. Springer, D. C. Anderson, A. S. Rosenthal, and R. Rothlein, editors. Springer-Verlag New York Inc. 138-148.

13. Williams, F. M., P. D. Collins, S. Nourshargh, and T. J. Williams. 1988. Suppression of 111 In-neutrophil accumulation in rabbit myocardium by MoA ischemic injury. J. Mol. Cell. Cardiol. 20:S33.

14. Simpson, P. J., R. F. Todd III, J. C. Fantone, J. K. Mickelson, J. D. Griffin, and B. R. Lucchesi. 1988. Reduction of experimental canine myocardial reperfusion injury by a monoclonal antibody (anti-Mol, anti-CD11b) that inhibits leukocyte adhesion. J. Clin. Invest. 81:624-629. 
15. Todd, R. F., III, P. J. Simpson, and B. R. Lucchesi. 1989. Anti-inflammatory properties of monoclonal anti-Mol (CD11b/CD18) antibodies in vitro and in vivo. In Leukocyte Adhesion Molecules: Structure, Function, and Regulation. T. A. Springer, D. C. Anderson, A. S. Rosenthal, and R. Rothlein, editors Springer-Verlag New York Inc. 125-137.

16. Simpson, P. J., R. F. Todd III, J. K. Mickelson, J. C. Fantone, K. P. Gallagher, K. A. Lee, Y. Tamura, M. Cronin, and B. R. Lucchesi. 1990. Sustained limitation of myocardial reperfusion injury by a monoclonal antibody that alters leukocyte function. Circulation. 81:226-237.

17. Richardson, C., A. DiPaula, J. Hildreth, and L. Becker. 1989. Failure of a monoclonal antibody directed against the neutrophil adhesion complex to reduce myocardial reperfusion injury. Circulation. 80(Suppl. II):II-401.

18. Tanaka, M., S. E. Brooks, G. P. Fitzharris, R. C. Stoler, R. B. Jennings, and K. A. Reimer. 1990. Effect of the IB4 anti-CD18 antibody on myocardial PMN accumulation and infarct size in dogs. FASEB (Fed. Am. Soc. Exp. Biol.) J. 4:A1020.

19. Dreyer, W. J., L. H. Michael, C. W. Smith, R. D. Rossen, R. Rothlein, M. L. Entman, and D. C. Anderson. 1990. Neutrophil localization in ischemic canine myocardium is attenuated by anti-CD18 monoclonal antibody R15.7. FASEB (Fed. Am. Soc. Exp. Biol.) J. 4:A893.(Abstr.)

20. Smith, C. W., R. Rothlein, B. J. Hughes, M. M. Mariscalco, H. E. Rudloff, F. C. Schmalstieg, and D. C. Anderson. 1988. Recognition of an endothelial determinant for CD18-dependent human neutrophil adherence and transendothelial migration. J. Clin. Invest. 82:1746-1756.

21. Smith, C. W., S. D. Marlin, R. Rothlein, M. B. Lawrence, L. V. McIntire, and D. C. Anderson. 1989. Role of ICAM-1 in the adherence of human neutrophils to human endothelial cells in vitro. In Leukocyte Adhesion Molecules: Structure, Function, and Regulation. T. A. Springer, D. C. Anderson, A. S. Rosenthal, and R. Rothlein, editors. Springer-Verlag New York Inc. 170-189.

22. Smith, C. W., S. D. Marlin, R. Rothlein, C. Toman, and D. C. Anderson 1989. Cooperative interactions of LFA-1 and Mac-1 with intercellular adhesion molecule-1 in facilitating adherence and transendothelial migration of human neutrophils in vitro. J. Clin. Invest. 83:2008-2017.

23. Zimmerman, G. A., and T. M. McIntyre. 1988. Neutrophil adherence to human endothelium in vitro occurs by CDw 18 (Mol, MAC-1/LFA-1/GP150,95) glycoprotein-dependent and -independent mechanisms. J. Clin. Invest. 81:531537.

24. Lo, S. K., G. A. Van Seventer, S. M. Levin, and S. D. Wright. 1989. Two leukocyte receptors (CD11a/CD18) mediate transient adhesion to endothelium by binding to different ligands. J. Immunol. 143:3325-3329.

25. Lo, S. K., P. A. Detmer, S. M. Levin, and S. D. Wright. 1989. Transient adhesion of neutrophils to endothelium. J. Exp. Med. 169:1779-1793.

26. Shappell, S. B., C. Toman, D. C. Anderson, A. A. Taylor, M. L. Entman, and C. W. Smith. 1990. Mac-1 (CD1 1b/CD18) mediates adherence-dependen hydrogen peroxide production by human and canine neutrophils. J. Immunol 144:2702-2711.

27. Tonnesen, M. G., D. C. Anderson, T. A. Springer, A. Knedler, N. Avdi, and P. M. Henson. 1989. Adherence of neutrophils to cultured human microvascular endothelial cells: stimulation by chemotactic peptides and lipid mediators and dependence upon the Mac-1, LFA-1, p150,95 glycoprotein family. J. Clin. Invest. 83:637-646.

28. Wright, S. D., S. K. Lo, and P. A. Detmers. 1989. Specificity and regulation of CD18-dependent adhesion. In Leukocyte Adhesion Molecules: Structure Function and Regulation. T. A. Springer, D. C. Anderson, R. Rothlein, and A.S. Rosenthal, editors. Springer-Verlag New York Inc. 190-207.

29. Anderson, D. C., L. J. Miller, F. C. Schmalstieg, R. Rothlein, and T. A. Springer. 1986. Contributions of the Mac-1 glycoprotein family to adherence-dependent granulocyte functions: structure-function assessments employing subunit-specific monoclonal antibodies. J. Immunol. 137:15-27.

30. Pohlman, T. H., K. A. Stanness, P. G. Beatty, H. D. Ochs, and J. M. Harlan. 1986. An endothelial cell surface factor(s) induced in vitro by lipopolysaccharide, interleukin-1, and tumor necrosis factor increases neutrophil adherence by a CDw18 (LFA)-dependent mechanism. J. Immunol. 136:4548-4553.

31. Gamble, J. R., J. M. Harlan, S. J. Klebanoff, and M. A. Vadas. 1985. Stimulation of the adherence of neutrophils to umbilical vein endothelium by human recombinant tumor necrosis factor. Proc. Natl. Acad. Sci. USA. 82:86678674.

32. Entman, M. L., K. Youker, S. B. Shappell, C. Siegel, R. Rothlein, W. J.
Dreyer, F. C. Schmalstieg, and C. W. Smith. 1990. Neutrophil adherence to isolated adult canine myocytes: evidence for a CD18-dependent mechanism. $J$. Clin. Invest. 85:1497-1506.

33. Dustin, M. L., R. Rothlein, A. K. Bhan, C. A. Dinarello, and T. A. Springer. 1986. Induction by IL-1 and interferon-gamma: tissue distribution, biochemistry, and function of a natural adherence molecule (ICAM-1). J. Immunol. 137:245-254.

34. Marlin, S. D., and T. A. Springer. 1987. Purified intercellular adhesion molecule-1 (ICAM-1) is a ligand for lymphocyte function-associated antigen (LFA-1). Cell. 51:813-819.

35. Makgoba, M. W, M. E Sanders, G. E Ginther Luce, M. L Dustin, T. A Springer, E. A. Clark, P. Mannoni, and S. Shaw. 1988. ICAM-1: definition by multiple antibodies of a ligand for LFA-1 dependent adhesion of B, T and myeloid cells. Nature (Lond.). 331:86-88.

36. Diamond, M. S., D. E. Staunton, A. R. deFougerolles, S. A. Stacker, J. Garcia-Aguilar, M. L. Hibbs, and T. A. Springer. 1990. ICAM-1 (CD54): a counter-receptor for Mac-1 (CD1 1b/CD18). J. Cell Biol. 111:3129-3139.

37. Anderson, D. C., K. L. B. Freeman, B. Heerdt, B. J. Hughes, R. M. Jack and C. W. Smith. 1987. Abnormal stimulated adherence of neonatal granulocytes: impaired induction of surface Mac-1 by chemotactic factors or secretagogues. Blood. 70:740-750.

38. Kamb, A., M. Weir, B. Rudy, H. Varmus, and C. Kenyon. 1989. Identification of genes from pattern formation, tyrosine kinase, and potassium channel families by DNA amplification. Proc. Natl. Acad. Sci. USA. 86:4372-4376.

39. Chomczynski, P., and N. Sacchi. 1987. Single-step method of RNA isolation by acid guanidinium thiocyanate-phenol-chloroform extraction. Anal. Biochem. 162:156-159.

40. Ballantyne, C. M., W. E. O'Brien, and A. L. Beaudet. 1989. Nucleotide sequence of the CDNA for murine intercellular adhesion molecule-1 (ICAM-1). Nucleic Acids Res. 17:5853.

41. Staunton, D. E., S. D. Marlin, C. Stratowa, M. L. Dustin, and T. A. Springer. 1988. Primary structure of intercellular adhesion molecule 1 (ICAM-1) demonstrates interaction between members of the immunoglobulin and integrin supergene families. Cell. 52:925-933.

42. Saiki, R. K., D. H. Gelfand, S. Stoffel, S. J. Scharf, R. Higuchi, G. T. Horn, K. B. Mullis, and H. A. Erlich. 1988. Primer-directed enzymatic amplification of DNA with a thermostable DNA polymerase. Science (Wash. DC). 239:487-491.

43. Maniatis, T., E. F. Fritsch, and J. Sambrook. 1989. Molecular Cloning: A Laboratory Manual. Cold Spring Harbor Laboratory, Cold Spring Harbor, New York.

44. Feinberg, A. P., and B. Vogelstein. 1983. A technique for radiolabeling DNA restriction endonuclease fragments to high specific activity. Anal. Biochem. 132:6-13.

45. Yanisch-Perron, C., J. Vieira, and J. Messing. 1985. Improved M13 phage cloning vectors and host strains: nucleotide sequences of the M13, M118 and pUC18 vectors. Gene (Amst.). 33:103-119.

46. Sanger, F., S. Nicklen, and A. R. Coulson. 1977. DNA sequencing with chain terminating inhibitors. Proc. Natl. Acad. Sci. USA. 74:5463-5468.

47. Ford, J. W., W. E. Burkel, and R. H. Kahn. 1981. Isolation of adult canine venous endothelium for tissue culture. In Vitro (Rockville). 17:44-50.

48. Pober, J. S., Jr., M. A. Gimbrone, L. A. Lapierre, D. L. Mendrick, W. Fiers, R. Rothlein, and T. A. Springer. 1986. Overlapping patterns of antigenic modulation by interleukin 1 , tumor necrosis factor and immune interferon. $J$. Immunol. 137:1893-1896.

49. Hernandez, L. A., M. B. Grisham, B. Twohig, K. E. Arfors, J. M. Harlan, and D. N. Granger. 1987. Role of neutrophils in ischemia-reperfusion-induced microvascular injury. Am. J. Physiol. 238:H699-H703.

50. Vedder, N. B., B. W. Fouty, R. K. Winn, J. M. Harlan, and C. L. Rice. 1989. Role of neutrophils in generalized reperfusion injury associated with resuscitation from shock. Surgery (St. Louis). 106:509.

51. Munro, J. M., J. S. Pober, and R. S. Cotran. 1989. Tumor necrosis factor and interferon-gamma induce distinct patterns of endothelial activation associated leukocyte accumulation in skin of papio anubis. Am. J. Pathol. 135:121133.

52. Furie, M. B., M. C. A. Tancinco, and C. W. Smith. 1991. Monoclonal antibodies to leukocyte integrins CD11a/CD18 and CD1 1b/CD18 or intercellular adhesion molecule-1 (ICAM-1) inhibit chemoattractant-stimulated neutrophil transendothelial migration in vitro. Blood. In press. 